NBER WORKING PAPER SERIES

\title{
RECONSIDERING THE ECONOMICS OF DEMAND ANALYSIS WITH KINKED BUDGET CONSTRAINTS
}

\author{
Aaron Strong \\ V. Kerry Smith \\ Working Paper 14304 \\ http://www.nber.org/papers/w14304 \\ NATIONAL BUREAU OF ECONOMIC RESEARCH \\ 1050 Massachusetts Avenue \\ Cambridge, MA 02138 \\ September 2008
}

Partial support for this research was provided by ASU's Decision Center for a Desert City. Thanks are due to Josh Abbott, Rob Williams, Chris Goemans, Jay Shimshack, the participants of the University of Colorado Workshop in Environmental and Resource Economics and two anonymous referees for comments and to Eric Moore and Jonathan Eyer for excellent research assistance and to Michael Tschudi for developing the GIS linkages between census and PAMA water provider service areas. The views expressed herein are those of the author(s) and do not necessarily reflect the views of the National Bureau of Economic Research.

NBER working papers are circulated for discussion and comment purposes. They have not been peerreviewed or been subject to the review by the NBER Board of Directors that accompanies official NBER publications.

(C) 2008 by Aaron Strong and V. Kerry Smith. All rights reserved. Short sections of text, not to exceed two paragraphs, may be quoted without explicit permission provided that full credit, including $\odot$ notice, is given to the source. 
Reconsidering the Economics of Demand Analysis with Kinked Budget Constraints Aaron Strong and V. Kerry Smith

NBER Working Paper No. 14304

September 2008

JEL No. H42,Q21

\begin{abstract}
$\underline{\text { ABSTRACT }}$
This paper has two objectives. First, we identify a problem with the ability of the discrete-continuous choice (DCC) framework and conditional demand functions to fully describe consumer preferences in the presence of kinked budget constraints. Second, we propose and illustrate an alternative, preference based, method for estimating consumer responses to price changes under these conditions. Our preference based approach yields price elasticities on the order of 0.4 and a "utilities expenditure" elasticity of near unity. This research highlights the possibility that households may be more sensitive to price schedules than previously thought. It is recognizes commitments to commodities such as pools or outdoor landscaping influence how water consumption responds to price changes as part of the long run adjustments.
\end{abstract}

\author{
Aaron Strong \\ University of Calgary \\ 2023 Keystone Ranch Rd. \\ Keystone, Colorado 80435 \\ strongaa@yahoo.com \\ V. Kerry Smith \\ Department of Economics \\ W.P. Carey School of Business \\ P.O. Box 873806 \\ Arizona State University \\ Tempe, AZ 85287-3806 \\ and NBER \\ kerry.smith@asu.edu
}




\section{Introduction}

This paper has two objectives. First, we identify a general problem in using the discrete-continuous choice (DCC) framework and conditional demand functions for applied welfare analysis with changes in kinked budget constraints. To illustrate the relevance of our argument, we consider the estimation issues that arise for the case of models for residential water demand with increasing block rate structures. Second, we propose an alternative, preference based, method for estimating consumer responses under these conditions. By specifying a direct utility function and estimating its parameters, our approach can evaluate policies that alter all the attributes of a block pricing structure. For the case of residential water demand, in many areas of the United States, especially in the arid Southwest, this type of change is being discussed as a component of increased incentives for conservation. ${ }^{1}$ At a national level, it is also part of EPA's policy known as the "Four Pillars of Sustainable Infrastructure.",

Conventional models for commodity demand (or labor supply) in the presence of a piece-wise linear budget constraints use a parametric specification for the conditional demand (labor supply) function to describe the selection of a "best facet" on the budget constraint and with it, an amount of the commodity demanded (or labor supplied). The choice is decomposed into the discrete and continuous components. This strategy has been widely adopted in describing labor supply responses including differences in participation status (i.e. working, retired, etc), and the extent of participation, part time

\footnotetext{
${ }^{1}$ In June 2007, U.S. News and World Reports profiled the global water problem. There continues to be professional and popular assessments raising concern about water management and availability (i.e. The Economist, December 8, 2007 and National Geographic, February, 2008) as well as renewed interest in economic research see Olmstead et al. [2007], Mansur and Olmstead [2006] and Chen and Hanak [2007].

2 The EPA Assistant Administrator for Water, Benjamin Grumbles in a 2006 briefing on EPA's water policies that current water prices signal it is available and cheap. This statement has been echoed in most of the popular assessments.
} 
vs. full time. It has also been an important component modeling of the strategies used to consistently estimate electricity and water demands in the presence of block rate pricing structures.

By contrast, our proposed method uses a different maintained assumption. It specifies household preferences using a direct utility function. As a result, there are also assumptions that underlie the model's results. One of the important questions arises from identification. That is, given a preference specification, a key issue concerns whether we can identify and estimate the structural parameters using the first order conditions from the constrained choice problem. The limited price variation usually encountered in applying the model to households in a single region can confound the ability to observe quantity adjustments.

We illustrate the logic for our method with an application to the residential water demand for the Phoenix, Arizona metropolitan area. Our empirical model uses monthly consumption data for 2005 for the "average" household (in a single family dwelling) in the service areas of each of 43 water service providers in the Phoenix Active Management Area (PAMA) of Arizona. By intersecting the GIS descriptions of the water providers' service areas with the GIS records for 2000 Census at the block group level and the Maricopa County (the county within PAMA) parcel records, we construct a set of economic, residential property, and demographic variables to serve as instruments. We compare our results for the preference model with the conventional DCC framework applied to the same sample and find the later yields insignificant income coefficients and smaller (in absolute magnitude) conditional price elasticity estimates. 
Section two describes the main elements of our argument. It begins by describing the DCC framework. After that, we explain one of the issues motivating this paper -an apparent contradiction between the Hausman [1979] interpretation of what is possible within the DCC framework and the Bockstael-McConnell [1981] conclusion about the difficulties facing welfare measurement with nonlinear budget constraints. With that background, we then summarize how Reiss and White [2006] explain the appropriate strategy for welfare measurement with nonlinear budget constraints. ${ }^{3}$ Within that context, we describe the problems with using the DCC logic to evaluate large changes in a block pricing structure for resources whose demands are largely determined by the utilization of complementary goods. Section three outlines the estimation strategy. Section four describes the data sources and five presents our results. The last section comments on the potential role measures of the responsiveness of water demand to major revisions in the price schedule can play in the design of policies intended to be part of developing sustainable infrastructure. ${ }^{4}$

\section{Background and Economic Consistency}

\section{A. Context}

Water demand is one of the prominent applications for models explaining consumer choice in the presence of kinked budget constraints. The Hewitt and Hanemann [1995] paper is the first, and arguably the most comprehensive, application of the DCC framework to water demand. Their analysis follows the general recommendations of

\footnotetext{
${ }^{3}$ To our knowledge, none of the water demand models have attempted to measure the consumer surplus associated with price changes. Most of their focus has been correctly measuring unconditional price elasticities in the presence of kinked budget constraints.

${ }^{4}$ For example see Hanak and Chen [2007].
} 
Hausman [1979] and Moffit [1986] for these situations. A conditional demand is specified. In their case, it is a constant elasticity function. The price and virtual income for the conditional demand are defined by the first stage selection of an optimal budget segment given the block pricing structure. Two errors are included in the specification. One represents optimization error and the second captures unobserved heterogeneity. Given assumed distributions for these errors (usually independent normality), observed water use, and knowledge of the specific features of the pricing structure faced by households, the framework defines the likelihood function for a sample of households' water consumption. Variation in the pricing structures, the maintained distributions for the errors, and the parametric specification for conditional demand function allows statistically consistent estimates to be developed.

The DCC model characterizes consumer preferences with the specification of a conditional demand function. The same functional form and parameterization is used to describe all of the segments of an increasing block rate structure. This restriction assures that the parameters can be identified. To illustrate our argument here, we selected the simplest of the popular specifications, a linear conditional demand given in equation (2.1):

$$
w_{i}=Z \gamma+\alpha p_{i}+\delta m_{i}
$$

Water is assumed to be priced with an increasing block rate structure with the nonlinear price for water defined as $c(w)$ and the form of the relationship given in equation (2.2). Assuming a two block pricing structure, $\bar{p}$ corresponds to the higher marginal price (the second block) and $\underline{p}$ the initial block's marginal price. $\hat{\mathrm{w}}$ is the 
threshold for the change in the marginal price (the amount of water defining kink point on the budget constraint ).

$$
c(w)=\left\{\begin{array}{cc}
\underline{p w} & \text { if } w \leq \hat{w} \\
\bar{p}(w-\hat{w})+\underline{p} \hat{w} & \text { if } w>\hat{w}
\end{array}\right.
$$

$Z$ is a vector of socio-demographic and household specific attributes, $p_{i}$ is the marginal price of the $i$ th block and $m_{i}$ is the virtual income of the $i$ th block. $m_{2}$, the virtual income of the second block, is defined by equation (2.3):

$$
m_{2}=m+(\bar{p}-\underline{p}) \hat{w}
$$

Following Hausman [1979], the quasi indirect utility function implied by this conditional demand specification is derived by Roy's identity. The first step links the specified conditional Marshallian demand from equation (2.1) to the relationship implied by Roy's identity in equation (2.4). This sequence describes how the differential equation given on the right hand side of the equation is related to the empirical demand function.

$$
-\frac{V_{p}}{V_{m}}=w=\frac{d m}{d p}=\alpha p+\delta m+Z \gamma
$$

Solving this differential equation yields equation (2.5), where $\mathrm{c}$ is the constant of integration:

$$
m=c e^{-\delta p}\left(\frac{\alpha}{\delta} p+\frac{\alpha}{\delta^{2}}+\frac{Z \gamma}{\delta}\right)
$$

As a rule, initial conditions help to relate $\mathrm{c}$ to the other factors that may influence the quantity demanded and also serve to provide the utility index. For our purposes, 
without loss of generality, we can write the expression for of the indirect utility function implied by this demand using equation $(2.6)^{5}$ :

$$
V(p, m)=e^{-\delta p}\left(m+\frac{\alpha}{\delta} p+\frac{\alpha}{\delta^{2}}+\frac{Z \gamma}{\delta}\right)
$$

A part of Hausman's argument for the model noted that the log likelihood function can be defined from the conditional demand functions. Thus, it is possible to recover parameter estimates for (2.6) using the conditional demand given in equation (2.1). It relies on the restriction of a common conditional demand specification for all facets of the budget constraint. Moreover, it restricts the demand parameters to be equal across all blocks. The estimator resembles one for interval censored data, adjusted to reflect the effect of block choice on the implied virtual income (i.e. actual income adjusted by the difference between what would be implied if all units consumed were priced at the marginal price implied by the selected price block and what each household actually pays as we have described in equation (2.3)). What is important about this logic is that it would appear that the estimated parameters of the conditional demand function contain sufficient information for welfare measurement when they are used in the scheme outlined by Reiss and White. However, this suggestion overlooks the importance of the assumption that conditional demand functions "look just like" unconditional demand functions aside from the adjustment to the income term. We can investigate the importance by examining the Reiss-White proposal in more detail.

\section{B. Welfare Analysis with the DCC Model}

\footnotetext{
${ }^{5}$ The direct utility function implied by equation is:

$U(w, x)=\exp \left(-\frac{\delta}{\alpha}\left(w+\frac{\alpha}{\delta}\right)\right) \exp \left(\delta^{2}\left(\frac{x}{\alpha}\right)\right) \exp \left(\frac{\delta}{\alpha}\left(\frac{\alpha}{\delta}+Z \gamma\right)\right)\left(\frac{w}{\delta}+\frac{\alpha}{\delta^{2}}\right)$
} 
A key conclusion of the earlier work discussing problems with applied welfare analysis in the presence of nonlinear budget constraints is that with a nonlinear budget constraint, the Marshallian "prices as parameters" demand function (or labor supply function) does not exist! Bockstael and McConnell [1983] made this point in discussing the implications of the household production function (HPF) framework for applied welfare analysis. Reiss and White's [2006] might seem to have proposed a resolution to the problem. However, their derivation of welfare measures with nonlinear prices relies on the ability to assume the existence of what appears to be an ordinary Marshallian demand function that can be integrated back to quasi-expenditure function. The resulting compensated demand is then used with the marginal price function to develop the welfare measures. This marginal price function helps in describing the path of price change.

Reconciling the two disparate arguments requires understanding the role for the assumed properties of the "Marshallian" demands defined for each value of the marginal price. Marginal prices can be continuous in the household production case considered by Bockstael and McConnell or they can change discretely for the kinked budget constraint due to block rate pricing. It is this relationship that is giving rise to the nonlinearity in the budget constraint. ${ }^{6}$ As Bockstael and McConnell demonstrate in note \#1 (p. 810) with a general nonlinear budget constraint, the features of preferences and nature of the constraint are scrambled. In their example, each of the marginal cost functions will imply a different slope for the Marshallian demand function. Reiss and White's argument requires that there exists a single Marshallian demand that describes how quantity

\footnotetext{
${ }^{6}$ It also influences the relationship between the sum of the quasi expenditure function and the infra marginal expenditure adjustment to derive the unobserved arguments needed for the Hicksian welfare measure in the Reiss and White [2006] framework. See 10-11 for their discussion.
} 
demand changes for each marginal price. ${ }^{7}$ This is essentially the same as what is being assumed in the DCC framework. We must assume preferences are consistent with an identical conditional demand for all price facets of the kinked budget constraint.

This requirement stands in contrast with conclusions from the literature on the econometrics of kinked budget constraints that appear much more general in their scope. For example, Hausman [1979] has argued that demand (or supply) functions can be estimated without instrumental variables or a weighted average of prices. Roy's identity, together with the convexity of the budget set, assure that the choice of segment and the quantity demanded can be based solely on the "demand functions."

The DCC framework describes the unconditional demand in a two step framework. A conditional demand function is used to describe both the choice of the "best" price segment on the kinked budget constraint as well as the quantity demanded, given the marginal price and virtual income implied by the first selection. The framework uses the logic implied by analytical (or numerical) solution to the differential equation defined by Roy's identity to compute the correct response in quantity demanded to a movement along one segment of the faceted budget constraint. However, as Reiss and White make clear, this result requires the assumption that a common (across facets)

\footnotetext{
${ }^{7}$ Following Edelfsen [1981] it is possible to define a relationship (correspondence) between the marginal price/cost implied by the nonlinear constraint for each value of this partial derivative and in principle numerically implements the Reiss-White logic. At each of the steps of the process, define the Marshallian relationship for that marginal price, apply a Vartian approximation and solve the implied extension to Reiss and White's two equation framework for a specific marginal price and utility level. A comparable issue arises with hedonic models and the definition of "demand" functions for the characteristics of heterogeneous goods. See Brown and Rosen [1982], Mendelsohn [1985] and Palmquist [2005] for discussion

${ }^{8}$ In the context of a labor supply framework, Hausman [1980] develops this conclusion directly citing his earlier result and concludes "... an econometric model of both labor force participation and labor supply can be based solely on a labor supply equation specification. Neither the direct not indirect utility function is needed" (p.165) This same argument has been applied to consumer demand models where decisions about budget segment and amount demanded parallel the choice of participation and extent of work in the labor supply literature.
} 
Marshallian conditional demand exists and describes demand responses correctly for all the marginal prices.

This logic has been applied in modeling water and electricity demands. In these cases, the demand is also conditional to another set of choices that are usually assumed to be made prior to the utilization decisions giving rise to water (or, in a similar context, electricity) usage patterns. As a rule, these cases involve equipment or durables associated with residence. Once we acknowledge that large changes in water price structures would influence these types of decisions then we must consider whether the envelope condition associated with re-evaluating commitments contains sufficient information to derive the associated "long run" demand response. In general, we cannot be assured it will!

To the extent the nature of the price schedule affects decisions to install pools or adopt different types of residential landscapes; those effects cannot be detected with the estimates derived from the DCC framework. The DCC logic assumes the responses to changes in the implied marginal price along with the infra-marginal expenditure adjustment is all that is needed to "predict" the optimal facet for water (or electricity). One realization of this assumption arises with the model requiring that the form of the conditional demand function and the values for its unknown parameters are constant across all facets of the budget constraint.

When we wish to re-design the price schedule in a general setting that assumes commitments to complementary goods might change, we do not have enough information to compute the marginal price and expenditure adjustments. These effects are important because it is often the case that policy makers are selecting higher priced blocks to 
discourage investments in high consumption complementary goods and therefore, the associated higher water consumption.

Reiss and White [2006] demonstrate that exact welfare measures can be derived in nonlinear pricing situations. They propose a four step logic:

(a) estimate ordinary demand functions relating quantity to the relevant marginal prices at the observe levels of the quantity demanded; ${ }^{9}$

(b) use these demand functions from (a) to recover the quasiexpenditure function analytically (Hausman [1981]) or numerically (Vartia [1983]) and derive the corresponding Hicksian demand; (as our example illustrated)

(c) at the observed quantity demanded, this expression for the Hicksian demand evaluated at an unknown constant marginal price and utility level should equal the inverse of the marginal price schedule also evaluated at this price; and finally,

(d) the initial level of utility realized at the initial nonlinear price schedule should be consistent with the total expenditures implied by the price schedule and the virtual income (i.e. Hicksian expenditures

\footnotetext{
${ }^{9}$ This first step is the practical constraint that avoids the numerical approach proposed by Edelfsen and described in footnote 3. To begin the process, the analyst must have an estimate of the Marshallian demand function. Without locally constant prices and the assumption of constant parameters across all price segments, we do not have the requisite demand function Reiss and White assume as a starting point.
} 
evaluated at the initial marginal price and utility plus the income

adjustment defined earlier). ${ }^{10}$

The equations defined by steps (c) and (d) provide two relationships and two unknowns - the initial marginal price consistent with the utility level realized and the level for the initial utility.

With these two variables, they demonstrate compensated demand defined in terms of an artificial constant marginal price can be used. A price schedule change is then recovered with the initial price and utility as well as the new price. Exact welfare is the integral under the compensated demand between the two marginal prices corrected by the change in the adjustment to income.

Reiss and White observe a big advantage of their logic is that:

“... a researcher can begin an empirically satisfactory model for the ordinary demand function ... and then compute exact consumer surplus under nonlinear prices without having to recover the direct utility function." (Reiss and White [2006] p. 12)

The problem with this logic is that it ignores the effects of changes in these conditional demands when the modifications in the price schedule are large enough to adjust quasi fixed goods, as we illustrate in the next section.

\section{Complementary Goods}

Suppose that $Z$ in equation (2.4) is a measure of the swimming pool or landscape structure that a household has committed to. It is reasonable to assume there are complementarities between either of these "goods" and water demand. The compensated demand response implied by equation (2.5) will consistently describe household

\footnotetext{
${ }^{10}$ This process is consistent with Epstein's [1981] discussion of consistent application of duality with nonlinear constraints. See his Theorem 5 and the example of household production functions.
} 
responses to changes in the marginal price only if the amount of $Z$ is consistent with equality of the Marshallian virtual price for $Z$ and the market price. Thus, we should expect:

$$
\frac{V_{Z}}{V_{m}}=p_{Z}
$$

with $V_{Z}$ and $V_{m}$ the partial derivatives of equation (2.6). Using the quasi indirect utility function (equation (2.6)) this envelop condition means $\gamma=\delta p_{Z}$. Substituting we can write Roy's identity for long run adjustments as:

$$
-\frac{V_{p}}{V_{m}}=\frac{d m}{d p}=\alpha p+\delta\left(m+p_{Z} Z\right)
$$

Suppose, however, the virtual price and market price cannot be assumed to be equal. In this case, the conditional demand specification for water is not enough information to describe how water demand would adjust in the long run as there are opportunities to modify these quasi-fixed commitments. We need some basis for describing how $Z$ would adjust to changes in $p$ and $p_{Z} \cdot{ }^{11}$ That is, to recover the full adjustment to changes in $p$ through the conditional demand, we are implicitly assuming the response implied by the envelop condition fully characterizes $Z$ 's adjustment. Solving Roy's identity uses changes in the water demand and $p$ as well as initial conditions. It tells us nothing about how $Z$ would adjust to non-local changes in $p$.

\footnotetext{
${ }^{11}$ This is not a new point. Hausman [1981] noted that we only learn about variations in the own price of the good with the solution of the differential equation implied by Roy's identity. As La France and Hanemann [1989] and von Haefen [2003] document, we need additional assumptions and a line integral for more price changes.
} 
To illustrate, suppose we assumed the demand for $Z$ was also linear and adjusted in the "long run." 12 Yet the demand given in equation (2.1) is a short run demand for water. Assume equation (2.9) describes the long run demand for $Z$. Using the envelop condition (2.7) and (2.9) we can illustrate why the Reiss-White procedure will not reflect the complementarities between $w$ and $Z$.

$$
Z=a+b m+c p_{Z}-d p
$$

Substituting into equation (2.8) for $Z$ and rearranging terms, we have (2.10)

$$
-\frac{V_{p}}{V_{m}}=\frac{d m}{d p}=\left(\alpha-\delta d p_{Z}\right) p+\delta\left(1-b p_{Z}\right) m+\delta a p_{Z}+\delta c^{2} p_{Z}^{2}
$$

This result illustrates how the long run demand for $w$ would imply that the marginal effect of $p$ on water demand depends on $p_{Z}$ (i.e. the first term in equation $(2.10))$.

We could, as sometimes proposed with another situation involving a nonlinear budget constraint, assume that the nonlinearity of the conditional demand is sufficient to identify a role for $Z$ 's adjustment. ${ }^{13}$ However, what is estimated will be conditional to the relationship between $Z$ and $p_{Z}$ in the envelop condition.

The DCC model decomposes water demand into two steps, the choice of a best segment and then, conditional on that selection, a demand response to changes in that segment's marginal price, given the adjustment to income required by the increasing block rate structure. In principle, goods that are complements for water such as

\footnotetext{
${ }^{12}$ Chetty and Szeidl [2007] used this argument in a dynamic setting to explain discrepancies between some types of behavior and measures of the coefficient of relative risk aversion. Assuming two classes of goods, food and committed consumption, they demonstrate that the income elasticity of food consumption is larger, implying greater food consumption response to income shocks with commitments than would be present without them.

${ }^{13}$ This was Brown and Rosen's [1982] argument. See Palmquist [2005] for further explanation and Chattopadyay [1999] for an example.
} 
swimming pools or landscape systems have demands that depend on the full price schedule for the water that is utilized with them. Once these commitments are made, they are quasi-fixed goods that influence the parameters of the Marshallian demand for water, as our simple example illustrates. Large changes in the price schedule are likely to change these commitments. They cannot be identified from the short run responses in the water usage alone. We illustrated this point in very simple terms by using the envelop condition together with an assumed demand function for one complementary good. The bottom line is we don't escape making additional assumptions. The single conditional demand function is not sufficient.

Arrufat and Zabalza [1986] identify a related issue in describing advantages of their use of a CES direct utility function to describe labor supply choices. They note that:

"... there are two reasons why, even when dealing with convex budget sets, it may be convenient to estimate a specific utility index. First, we may want to use our estimates to predict the effects of introducing non-convexities in the budget constraint ... unless we have at our disposal an explicit utility index, in either direct or indirect form, we will not be able to predict behavioral responses to these types of changes in the opportunity set. Second, and less obvious, if there exist optimization errors ... the conventional measures of welfare change cannot be inferred from areas under market supply curves (even if compensated), since neither initial nor final positions will correspond to tangency positions." (p.48, emphasis added)

This discussion recognizes that the estimates from the demand model approach do not permit analysis of large scale reform in pricing (or tax) structures.

\section{Model}

Our alternative model begins with a specification for the direct utility function. We believe that this strategy offers a more transparent basis for characterizing 
relationships between water and the complementary goods that influence how water is used. This approach relies on a composite of structural restrictions as well as the need to observe sufficient variation in the price schedules for water along with household conditions to identify and estimate the parameters of that preference function.

As a practical matter, commodities such as water, electricity and other utilities are associated with a small fraction of budget. Small price changes in any one of them are unlikely to induce large re-allocation of income among all goods. This feature of demand can compound the difficulties in estimating household demand. The effects of small price changes may primarily induce re-allocation of the expenditures on household utilities. Recognizing this prospect for estimation of the preference parameters using data with limited variation in the price structures, we assume utilities enter preferences in a separable sub-function and treat their expenditures as a fraction of income that varies with income. Our estimates for this share are based on the Consumer Expenditure Survey (CES) average for utilities (including water). In 2006, they identified thirteen different income classes (see BLS [2007]). ${ }^{14}$

The preference specification describing the choice of utilities corresponds to the von Haefen et. al [2004] direct utility function and is given in equation $(3.1)^{15}$

$$
U(w, x)=\frac{1}{\rho_{w}} \exp (Z \delta+\varepsilon)(\exp (q \beta) w+\theta)^{\rho_{\omega}}+\frac{1}{\rho_{x}} x^{\rho_{x}}
$$

\footnotetext{
${ }^{14}$ Our sample is composed of average consumption levels and there are no area specific measures of these expenditure shares at the level of census data. To account for differences with income we use the census measures of household income for each water provider's service area along with the CES to assign one of thirteen different values for the expenditure share ranging from about .068 to .108 .

${ }^{15}$ This is based on Hanemann's [1984] earlier proposed model for generalized corner solution model.
} 
If we assume the expenditure on this component of a household's budget is $m=s y$ (with $s$ equal to a value based on household income), then we can embed the budget constraint into the utility function. As in equation (3.2):

$$
U(w)=\frac{1}{\rho_{w}} \exp (Z \delta+\varepsilon)(\exp (q \beta) w+\theta)^{\rho_{\omega}}+\frac{1}{\rho_{x}}(m-c(w))^{\rho_{x}}
$$

$m-c(w)$ corresponds to a household's virtual expenditures on the other components of utilities and will depend on the block rate structure faced by each household (see Hewitt and Hanemann [1995] for a detailed discussion). $Z$ is a matrix of socio-demographic variables, $q$ is matrix of water specific attributes such as lot size, and presence of a pool, $\theta$ is a demand shift parameter (e.g. similar to a threshold consumption in a Stone-Geary specification) that also contains the identification of summer vs. winter time span, and $\rho_{\omega}$ and $\rho_{x}$ are substitution parameters. ${ }^{16}$ The complementary goods (treated as quasi-fixed commitments) enter the utility function as part of a scaling function. This is consistent with the utilization logic described earlier. By specifying the direct utility function, we include the equivalent of the information that would be needed in the set of long run demands for complementary goods. The expression, $\exp (q \beta) w+\theta$, can be considered as a quality adjusted, or quantity augmentation based on prior commitments, measure for the use of water. The first of these interpretations is similar to that of von Haefen et al. [2004] in a recreation application.

Further intuition for these parameters, can be offered by recognizing that this function is a variation on Mukerji's [1963] constant ratio of elasticity of substitution function. The Hanemann-Von Haefen et al. function can be derived using a monotonic

\footnotetext{
${ }^{16}$ These two parameters implicitly allow for complementary or substitute relationships between the quantity of water consumed and these other goods.
} 
transformation of the Mukerji generalization of the CES function. This re-casting of the model allows Smith's[1974] derivation of the price and income elasticities implied by this function to be used to describe local responsiveness within budget segments and thus to compare the estimates implied by the function with what has been derived using conditional demand functions within a DCC framework. ${ }^{17}$

The estimating equation for the model's parameters uses the first order condition for the local optimization component of the household's budget and is given in equation (3.3):

$$
\exp (Z \delta+\varepsilon) \exp (q \beta)(\exp (q \beta) w+\theta)^{\rho_{\omega}-1}+c^{\prime}(w)(m-c(w))^{\rho_{x}-1}=0
$$

It is able to include the implications of the kinked budget constraint by defining $m_{i}$ as the virtual available income for utilities in block $i$ and $p_{i}$ the relevant marginal price. The expression is conditional on the block selected. Water demand, price, and expenditures on remaining utilities (i.e. $\left.m_{i}-p_{i} w\right)$ are all endogenous variables. Taking natural logarithms of (3) and re-arranging terms, yields equation (3.4).

$$
\ln \left(p_{i}\right)=Z \delta+q \beta+\left(\rho_{w}-1\right) \ln (\exp (q \beta) w+\theta)+\left(1-\rho_{x}\right) \ln \left(m_{i}-p_{i} w\right)+\varepsilon
$$

$\varepsilon$ can be assumed to correspond to either optimization error or unobserved household heterogeneity.

Our analysis does not confront the issues associated with choice at the kinks of the budget constraint versus tangencies to a facet. As we discuss below, the use of consumption for an "average" household implies that all choices can be interpreted as tangencies with optimization errors that are on average zero. Our framework uses GIS

\footnotetext{
${ }^{17}$ An analysis of the responses to changes in the full price schedule is also possible and would require simulating the constrained optimization for different price schedules. This is outside the scope of this paper.
} 
methods to intersect water service provider service areas with Census block areas for Maricopa County as well as with the parcel records for residential properties. These variables characterize water providers' customers. They are used to define instruments for the quantity of water demanded and virtual expenditures. 


\section{Data}

\section{A. Background}

Ideally, our model (and the DCC specification) would be applied with household level data. These data are generally not in the public domain. When studies have had access to micro data they often span wide geographic domains with quite different patterns of water use or they have very limited price variation. Olmstead et al. [2007] is an example of the first situation and Pint [1999], the second.

We illustrate our model and compare it to the DCC framework using data that are consistently in the public domain. These data are based on average household water usage for residential customers in each of a set of water providers. We exploit the variation in price schedules and construct the bill that would have resulted for a household with this water usage for each provider. Thus, our example considers a potentially important issue that is secondary to the main objective of the paper. That is, we investigate whether differences in modeling assumptions between a preference based formulation and the DCC model can be detected with relatively "coarse" aggregate data.

\section{B. Data Sources}

The Phoenix Active Management Area is shown in Figure 1 and corresponds to approximately the northern two-thirds of Maricopa County. It encompasses all of what would be considered the Phoenix Metropolitan area. The data for our application were collected from a variety of sources. The 2005 price schedule for each water service provider is reported by the Arizona Water Infrastructure Financing Authority. Table 1 summarizes the features of these price schedules. The first panel highlights the variation 
in the price schedule across providers. Each element in the table displays the range of marginal prices (per thousand gallons) for each block. The second panel provides the average width of the blocks across the uniform, two, three and four block schedules. Each is measured in gallons.

Information on aggregate single family consumption in 2005 and number of single family customers was obtained from imaged records of the Arizona Department of Water Resources' Schedule F available for monthly water consumption by residence type. These data allow construction of water used by an "average" single family residential consumer. Based on that monthly water consumption and each provider's price schedule we can recover measures for their marginal price and expenditures on water. These two datasets provide 516 provider/month observations for water consumption and price schedule information.

Census data for 2000 were adapted to conform to the service areas of each of the providers to construct measures of expenditures on utilities as well as other economic and demographic variables characterizing their customers. This was accomplished by intersecting the Census block groups with the water service provider areas. ${ }^{18}$ Average household income together with the CES schedule of the proportions of income spent on utilities by income class was used to construct the total expenditures on utilities for each area. The parcel records from the Maricopa County Assessor were used to develop summary statistics for housing measures at the Census block group level and ultimately

\footnotetext{
${ }^{18}$ The construction of the demographic information required intersecting the service provider areas with the census block groups. Two statistics were defined: (1) the percentage of each block group contained in the service provider area; and (2) the percentage of the service provider area contained in each of the block groups. The first was used to aggregate census variables describing distributions (e.g. income, race, etc.) and the second for summary statistics such as means or medians
} 
intersected with water service provider areas. This allows measurement of the percentage of households with pools located in a given service provider area. To control for climatic conditions monthly data on cooling degree days with a $65^{\circ}$ baseline and total precipitation during the month were obtained from the National Climatic Data Center of NOAA for the Phoenix Sky Harbor Airport station.

There are approximately 60 water service providers that serve the Phoenix Metropolitan area. Of these, 43 have complete records for residential customers in single family dwellings. The first panel of Table 2 provides some summary statistics for the demographic characteristics for the residential customers across providers. The second panel in the table summarizes the variation in temperature and precipitation across the months in our sample. The majority of the water service providers that we eliminated are simply irrigation districts that may provide water to a few households usually at a fixed cost. ${ }^{19}$

As with most water studies such as Hewitt and Hanemann [1995] and Olmstead et al. [2007], we are exploiting structural restrictions inherent in our model as well as the variation across water service providers in price schedules, socio-demographic, and housing characteristics to identify the model's parameters. All of these water service providers are in the Phoenix metropolitan area. There is no variation in linked weather conditions across water service providers because they are derived from a single weather station. Weather related variables vary with the month of consumption.

\footnotetext{
${ }^{19}$ The only other reason a provider was deleted from consideration stemmed from the fact that they are not required to report monthly consumption. The size of the water service provider's service area determines these reporting requirements.
} 


\section{Results}

We present the estimates for the DCC model as well as our proposed alternative framework. The findings for our model are presented first. Our alternative framework does need to consider endogeneity of price, water consumption, and net income. Two estimators are considered for our model. The first develops instruments for the log of the average household's expenditures on other utilities (taking account of the implications of the block pricing structure for the virtual income available) and the average water consumption by month using the predictions from first stage regression models that include temperature degree days, total monthly precipitation, the percentage of houses with pools, the average house value (as assessed by homeowners in the census), total number of lots in the service area, and number of rental units. These GIS constructed variables compromise the instruments in the first estimator. A simple model with fixed effects for each water service providers together with the weather variables is the second. The first stage estimates for the first of these estimators are given in Table 3.

The estimates for the preference model parameters using each of the two sets of instruments are given in Table 4 . Both models specify the $Z$ matrix as composed of a vector of ones (for an intercept), our temperature measure, and the number of customers the water service provider serves. $q$ contains the percentage of pools in the service provider area; and $\theta$ contains a constant and dummy variables identifying whether the monthly consumption was during the summer and winter periods. ${ }^{20}$ The shoulder period between summer and winter is the omitted category. We estimate equation (3.4) using non-linear least squares with each set of instruments.

\footnotetext{
${ }^{20}$ Summer is defined as June, July, August and September where as winter is defined as December, January, February and March.
} 
The estimates based on the demographic, economic, and weather variable instruments yield more precise results for the model. With instruments based on the provider fixed effects we find the model attributes all the price variation to the provider effects. This is important because differences in the price schedules along with the variation in the average household's water consumption in each provider's residential customer class provide the variation in marginal prices. With provider fixed effects used to define instruments it appears that the variation in the price schedule is being captured completely by these variables. As a result, it is not surprising that the parameter estimates are not significant. A Hausman [1978] specification test decisively rejects the fixed effects specification $\left(\chi^{2}=115.83\right.$ with $p$-value $\left.=0.00\right) .{ }^{21}$

To evaluate these estimates further, we computed the price and "utilities expenditures" elasticities at the sample mean for the price of water and for the virtual utilities expenditures. These results are given in panel A of Table 5. Below each estimate we report the Z-statistic based on the asymptotic standard errors. In addition, we computed the elasticity for each month and water provider. A summary of these results is given in panel $\mathrm{B}$-with the mean, median and the minimum and maximum values across the providers in the summer months.

There are several caveats in interpreting these estimates. These measures are not the estimates that would be implied with a change in the structure of the increasing block rate structure. They apply to local changes. Our approach recovers estimates of all the preference parameters that would be required to derive a response to a large change in the price structure. Indeed, this is a key motivation for the model. We report these local

\footnotetext{
${ }^{21}$ We conducted this test with and without the intercept and the results in both cases favor the model using the GIS constructed instruments over that based on provider fixed effects.
} 
price and expenditure elasticities because they are comparable to most of the literature and are more comparable to the elasticities implied by the conditional demands estimated with the DCC framework. ${ }^{22}$ In our case, measures of the demand responses to large changes require computation of the solutions to the constrained optimization problems associated with a baseline price structure and the proposed change.

Our estimates are also conditioned by the maintained separability assumption we discussed at the outset. This restriction influences how the estimates can be compared with findings from the existing literature. For the income elasticity, the relationship is straightforward, provided we interpret the response to an income change as a marginal change to a pre-existing optimal water consumption choice. $\sigma_{w y}=\sigma_{w s} \sigma_{s y}$, with $\sigma_{w y}$ the conventional income elasticity of demand; $\sigma_{w s}$ the utilities expenditure elasticity (i.e. what we estimated); and $\sigma_{s y}$ the elasticity of the composite of utilities expenditures with respect to household income. Using estimates for $\sigma_{s y}$ from the literature, we can adapt the results in Table 4 to develop a measure of the income elasticity implied by our findings. For example, Blanciforti and Green [1983] report an estimate of $\sigma_{s y}=0.62 .{ }^{23}$ This implies our estimate for the income elasticity of demand for water using the measures for $\sigma_{w s}$ of 0.63 (i.e. $0.62 * 1.02$ )

The price elasticities also require some adjustment $\left(\sigma_{w p}=\eta_{w p}-\sigma_{w s} \sigma_{m p}\right)$ where $\eta_{w p}$ is our estimate for the price elasticity, holding the utilities expenditures constant and

\footnotetext{
${ }^{22}$ In their appendix, Olmstead et al. document the simulation methods used to develop measures for elasticities for the unconditional demand.

${ }^{23}$ More recently Taylor [2005] has estimated income elasticities using the consumer expenditure survey. His results range from 0.31-0.42 for 1999 cross specifications for a category he designates as utilities. Water is not separately identified in the ACCRA price indexes he uses with the expenditure survey. Water expenditure are included in the consumer expenditure survey. So strictly speaking his price index fails to reflect the covariation in their prices
} 
$\sigma_{m p}$ is the elasticity of these expenditures with respect to the price of water, holding

income constant. Since we are expressing the price elasticities as in absolute magnitudes these expressions imply the comparable "unconditional" price elasticity would be smaller than our estimates. ${ }^{24}$

As noted at the outset, we estimated the DCC model using a constant elasticity specification of the conditional demand function to compare our results. We follow Hewitt and Hanemann [1995], Waldman [2000] and Olmstead et al. [2007] in our structuring of the model. Table 6 shows two sets of parameter estimates for DCC model -using the expenditure on utilities as the income measure in the first column and average income in the second. Several aspects of the results should be noted. First, applications of the DCC model to date have used micro data. Our findings that the variance of the optimization error is larger than the unobserved heterogeneity $\left(\sigma_{\eta}>\sigma_{\varepsilon}\right)$, are likely due to the structure of our data. Second, the price elasticity for the conditional demand elasticity is comparable in magnitude to our estimate of the local elasticity using the preference model. However, there is a striking difference in the income elasticity estimates. Under the DCC model, there is an insignificant income effect. By contrast, our estimates of the income elasticity using the preference function are close to unity.

Comparisons of the local price elasticity measures (in Table 5) from our preference model compared to the conditional elasticity estimates with the DCC model indicate that they are quite consistent. While a statistical test for the difference between these estimates is not possible, their relative proximity suggest, for practical purposes,

\footnotetext{
${ }^{24}$ We were unable to locate estimates of the responsiveness of utility expenditures to the price of water do not appear to have been developed.
} 
they would not imply differences in local responsiveness to small changes in price. This is not surprising since the two models are describing "average" responsiveness.

The important feature of our proposed method is the ability to recover the structural parameters required for evaluating large scale changes. Indeed, with micro data and greater detail on swimming pools, landscape infrastructure and variables describing other large water using capital decisions we could relax the assumption that the share of expenditures on utilities varies on with income and expand the range of structural parameters estimated with the framework.

\section{Summary and Implications}

This paper argues that the conventional approach for analyzing commodity demand in the presence of kinked budget constraints cannot evaluate the implications of large changes in the pricing structure for water. Moreover, it relies on the assumption of a constant conditional demand function across different marginal price segments in an increasing block rate structure. We proposed an alternative that uses a preference specification as the primitive in estimation. It allows us to consider welfare changes to large scale changes in the price structure. The data available for our application, while comparable to the most common information available for characterizing water demand, describes the "average" response rather than the individual household response.

Aggregate data for all residential customers served by 43 water service providers in the Phoenix area are used to estimate our preference based model and a version of the DCC model. 
An application to the "average" residential customer based on aggregate data is of interest because these data are what is readily available for most water demand applications. To date, the DCC model has been exclusively associated with applications with access to extensive household level water consumption data as well as sufficient price variation to recover demand responsiveness. When these data do not exist, policy analysts are forced to adapt existing (and often old estimates) to describe how household's water demand responds to changes in the block rate pricing structure.

Our strategy exploits the economic and demographic diversity of households along with GIS techniques to characterize the demographic and economic features of the spatially delineated service areas for the water providers included in our sample. In addition, rather than derive an estimator that uses the preference function to predict the facet of the budget constraint selected and then the amount of the commodity demanded, we focus on developing instruments for the choice variables and estimating parameters of the separable sub-function of preferences. With detailed micro records, our framework could be extended using the two error framework and logic comparable to Zabalza's work to develop a maximum likelihood estimator. These are the types of estimates needed to address the challenge of designing price structures that encourage water conservation by reflecting the full costs of complementary, water using, capital goods. 
Table 1: Summary of Price Schedules in the PAMA

\begin{tabular}{|c|c|c|c|c|c|c|c|}
\hline \multicolumn{8}{|c|}{ Range of Prices by Price Structure } \\
\hline Schedule & Providers & \multicolumn{2}{|c|}{$\begin{array}{c}\text { Service } \\
\text { Charge } \\
\text { (average) }\end{array}$} & Block 1 & Block 2 & Block 3 & Block 4 \\
\hline Uniform & 7 & & 14.49 & 1.75-2.86 & & & \\
\hline $\begin{array}{l}\text { Two } \\
\text { Block }\end{array}$ & 13 & & 12.43 & $0-4.10$ & 0.35-3.00 & & \\
\hline $\begin{array}{l}\text { Three } \\
\text { Block }\end{array}$ & 20 & & 12.31 & 0-6.80 & 0.68-10.2 & $1.00-12.30$ & \\
\hline $\begin{array}{l}\text { Four } \\
\text { Block } \\
\end{array}$ & 3 & & 13.41 & $\mathbf{0}$ & 1.26-1.68 & 1.59-2.54 & 2.04-3.05 \\
\hline \multicolumn{8}{|c|}{ Average Block Width by Price Structure in gallons } \\
\hline & \multicolumn{2}{|c|}{ Providers } & & Block 1 & \multicolumn{2}{|c|}{ Block 2} & Block 3 \\
\hline Uniform & \multicolumn{2}{|c|}{7} & & & & & \\
\hline $\begin{array}{l}\text { Two } \\
\text { Block }\end{array}$ & \multicolumn{2}{|l|}{13} & \multicolumn{2}{|r|}{7267} & & & \\
\hline $\begin{array}{l}\text { Three } \\
\text { Block }\end{array}$ & \multicolumn{2}{|l|}{20} & \multicolumn{2}{|r|}{6115} & \multicolumn{2}{|c|}{12335} & \\
\hline $\begin{array}{l}\text { Four } \\
\text { Block }\end{array}$ & \multicolumn{2}{|l|}{3} & & 2333 & \multicolumn{2}{|c|}{6333} & 10000 \\
\hline
\end{tabular}

Table 2: Summary Statistics for Socio-Demographic and Weather Variables

\begin{tabular}{|c|c|c|c|c|}
\hline \multicolumn{5}{|c|}{ Summary Statistics for Socio-demographic variables } \\
\hline Variable & Mean & Std. Dev. & Min & Max \\
\hline $\begin{array}{l}\text { Mean Income } \\
(2000 \text { dollars })\end{array}$ & 74932.56 & 41385.67 & 36938.75 & 213128.3 \\
\hline $\begin{array}{l}\text { Number } \\
\text { Customers }\end{array}$ & 22540.79 & 58141.49 & 20 & 365499 \\
\hline $\begin{array}{l}\text { Average } \\
\text { Consumption } \\
\text { (gallons) } \\
\end{array}$ & 13721.19 & 11705.32 & 2530.141 & 110690.5 \\
\hline Percentage Pools & 0.2155752 & 0.1883112 & 0.0375906 & 0.8913924 \\
\hline $\begin{array}{l}\text { Mean House } \\
\text { Value ( } 2000 \\
\text { dollars) }\end{array}$ & 164898.2 & 111843.6 & 54761.38 & 539851.4 \\
\hline $\begin{array}{l}\text { Total Residential } \\
\text { Lots }\end{array}$ & 25235.86 & 75519.2 & 8.266092 & 486640.1 \\
\hline Total Rental Units & 7121.07 & 28172.17 & 0.0333717 & 183255.1 \\
\hline \multicolumn{5}{|c|}{ Summary of Weather Variables } \\
\hline Variable & Mean & Std. Dev. & Min & Max \\
\hline $\begin{array}{l}\text { Temperature } \\
\text { (Cooling degree } \\
\text { days) }\end{array}$ & 392.4167 & 363.2004 & 0 & 1005 \\
\hline Precipitation $(\mathrm{cm})$ & 58.66667 & 91.56129 & 0 & 301 \\
\hline
\end{tabular}


Table 3: First stage regression of expenditures and water consumption

\begin{tabular}{|c|c|c|}
\hline Parameter & Expenditures $^{\mathrm{a}}$ & Water $^{\mathrm{a}}$ \\
\hline Constant & $\begin{array}{c}5.84 \\
(401)\end{array}$ & $\begin{array}{l}4086 \\
(4.45)\end{array}$ \\
\hline Temperature & $\begin{array}{c}\left(-3.90 \times 10^{-5}\right) \\
(-2.20)\end{array}$ & $\begin{array}{c}8.62 \\
(7.38)\end{array}$ \\
\hline Precipitation & $\begin{array}{c}4.16 \times 10^{5} \\
(0.59)\end{array}$ & $\begin{array}{l}-10.40 \\
(-2.24) \\
\end{array}$ \\
\hline$\%$ pools & $\begin{array}{c}.694 \\
(8.00)\end{array}$ & $\begin{array}{l}28279 \\
(4.94)\end{array}$ \\
\hline House value & $\begin{array}{c}7.59 \times 10^{-7} \\
(7.16)\end{array}$ & $\begin{array}{c}0.00809 \\
(1.16)\end{array}$ \\
\hline Total Lots & $\begin{array}{c}2.47 \times 10^{-6} \\
(5.16)\end{array}$ & $\begin{array}{c}-0.0979 \\
(-3.10)\end{array}$ \\
\hline Rental Units & $\begin{array}{c}-5.70 \times 10^{-6} \\
(-4.46)\end{array}$ & $\begin{array}{l}0.231 \\
(2.75)\end{array}$ \\
\hline $\mathrm{R}^{2}$ & 0.76 & 0.40 \\
\hline
\end{tabular}


Table 4: Estimates of Utilities Sub-function ${ }^{\text {a }}$

\begin{tabular}{|c|c|c|}
\hline Parameter $^{\mathrm{b}}$ & $\begin{array}{c}\text { Provider } \\
\text { Households } \\
(1) \\
\end{array}$ & $\begin{array}{l}\text { Fixed Effects } \\
\text { (2) }\end{array}$ \\
\hline $\mathrm{Z}_{\text {constant }}$ & $\begin{array}{l}-19.48 \\
(-5.24)\end{array}$ & $\begin{array}{l}-73.38 \\
(-0.18)\end{array}$ \\
\hline $\mathrm{Z}_{\mathrm{Temp}}$ & $\begin{array}{c}-.65 \times 10^{-4} \\
(-0.52)\end{array}$ & $\begin{array}{c}.20 \times 10^{-3} \\
(0.30)\end{array}$ \\
\hline$Z_{\text {no cust }}$ & $\begin{array}{c}5.76 \times 10^{-7} \\
(1.91)\end{array}$ & $\begin{array}{c}1.70 \times 10^{-7} \\
(0.58)\end{array}$ \\
\hline $\mathrm{q}_{\text {pools }}$ & $\begin{array}{c}-3.08 \\
(-7.08)\end{array}$ & $\begin{array}{c}.14 \\
(0.50) \\
\end{array}$ \\
\hline$\theta_{\text {constant }}$ & $\begin{array}{c}-1088.48 \\
(-1.08) \\
\end{array}$ & $\begin{array}{c}-2746.21 \\
(-0.05) \\
\end{array}$ \\
\hline$\theta_{\text {summer }}$ & $\begin{array}{r}314.03 \\
(0.28) \\
\end{array}$ & $\begin{array}{r}278.58 \\
(0.08) \\
\end{array}$ \\
\hline$\theta_{\text {winter }}$ & $\begin{array}{c}1119.53 \\
(1.87) \\
\end{array}$ & $\begin{array}{c}903.84 \\
(0.23) \\
\end{array}$ \\
\hline$\rho_{\text {water }}$ & $\begin{array}{c}.41 \\
(2.35) \\
\end{array}$ & $\begin{array}{c}.51 \\
(0.10) \\
\end{array}$ \\
\hline $\begin{array}{l}\qquad \rho_{\text {numeraire (utilities other }} \\
\text { than water) }\end{array}$ & $\begin{array}{c}2.94 \\
(5.46) \\
\end{array}$ & $\begin{array}{l}11.75 \\
(0.20) \\
\end{array}$ \\
\hline \multicolumn{3}{|c|}{$\begin{array}{l}{ }^{\mathrm{a}} \text { The number in parentheses are the z-statistics for the null hypothesis of no association. The } \\
\text { estimates were derived with non-linear least squares, replacing expenditures net of water and water demand } \\
\text { with instruments. } \\
\qquad{ }^{\mathrm{b}} \mathrm{Z}_{\text {Temp }} \text { is cooling degree days that roughly corresponds to the effects of temperature on the growth } \\
\text { of grasses, } Z_{\text {no cust }} \text { is the number of customers in the service provider area, qpools is the percentage of } \\
\text { residential lots with pools in the service provider area, } \theta_{\text {summer }} \text { and } \theta_{\text {winter }} \text { are dummy variables for months in } \\
\text { the summer and winter, respectively, with the shoulder periods between winter and summer as the omitted } \\
\text { category. }\end{array}$} \\
\hline
\end{tabular}


Table 5: Estimated Price and "Income" Elasticities

\begin{tabular}{|c|c|c|c|c|}
\hline \multicolumn{5}{|c|}{ A. Computed elasticities at the mean value of water and utility expenditures ${ }^{\mathrm{a}}$} \\
\hline \multirow[t]{2}{*}{ Elasticity } & \multicolumn{2}{|c|}{$\begin{array}{c}\text { Provider Households } \\
\text { (1) }\end{array}$} & \multicolumn{2}{|c|}{$\begin{array}{c}\text { Fixed Effects } \\
(2)\end{array}$} \\
\hline & Summer & Winter & Summer & Winter \\
\hline $\begin{array}{l}\text { Own price } \\
\text { (absolute } \\
\text { magnitude) }\end{array}$ & $\begin{array}{c}0.41 \\
(7.25)\end{array}$ & $\begin{array}{c}0.38 \\
(6.38)\end{array}$ & $\begin{array}{c}.165 \\
(0.74)\end{array}$ & $\begin{array}{l}.125 \\
(0.50)\end{array}$ \\
\hline $\begin{array}{l}\text { Utility } \\
\text { Expenditure }\end{array}$ & $\begin{array}{c}1.01 \\
(1970)\end{array}$ & $\begin{array}{c}1.02 \\
(1037) \\
\end{array}$ & $\begin{array}{c}1.01 \\
(510) \\
\end{array}$ & $\begin{array}{l}1.02 \\
(269) \\
\end{array}$ \\
\hline Income & 0.62 & 0.62 & 0.62 & 0.62 \\
\hline \multicolumn{5}{|c|}{ B. Computed elasticities for each provider - summary for summer months ${ }^{b}$} \\
\hline \multicolumn{5}{|c|}{ Own price (absolute magnitude) } \\
\hline Mean & \multicolumn{2}{|c|}{.404} & \multicolumn{2}{|c|}{.158} \\
\hline Median & \multicolumn{2}{|c|}{.398} & \multicolumn{2}{|c|}{.154} \\
\hline Min & \multicolumn{2}{|c|}{.341} & \multicolumn{2}{|c|}{.103} \\
\hline Max & \multicolumn{2}{|c|}{.365} & \multicolumn{2}{|c|}{.302} \\
\hline \multicolumn{5}{|c|}{ Utility Expenditure } \\
\hline Mean & \multicolumn{2}{|c|}{1.017} & \multicolumn{2}{|c|}{1.032} \\
\hline Median & \multicolumn{2}{|c|}{1.013} & \multicolumn{2}{|c|}{1.014} \\
\hline Min & \multicolumn{2}{|c|}{1.004} & \multicolumn{2}{|c|}{1.004} \\
\hline Max & \multicolumn{2}{|c|}{1.073} & \multicolumn{2}{|c|}{1.028} \\
\hline \multicolumn{5}{|c|}{$\begin{array}{l}{ }^{\mathrm{a}} \text { The number in parentheses are the z-statistics for the null hypothesis of no association. } \\
\text { b } \text { The first column corresponds to estimates using the model with instruments based on economic } \\
\text { and demographic characteristics of each provider service area. The second column uses the provider fixed } \\
\text { effects as instruments }\end{array}$} \\
\hline
\end{tabular}


Table 6: DCC Model Estimates

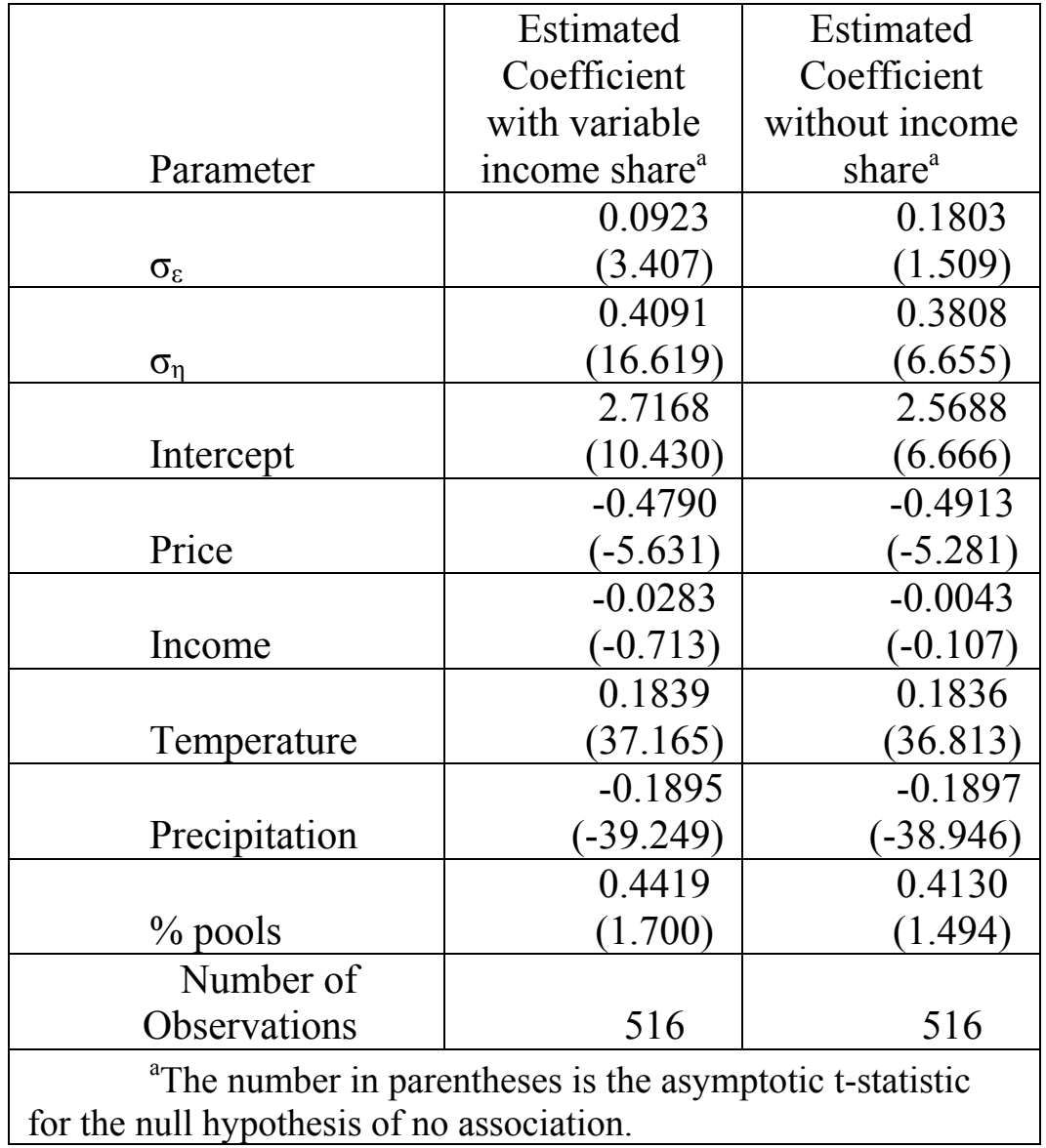




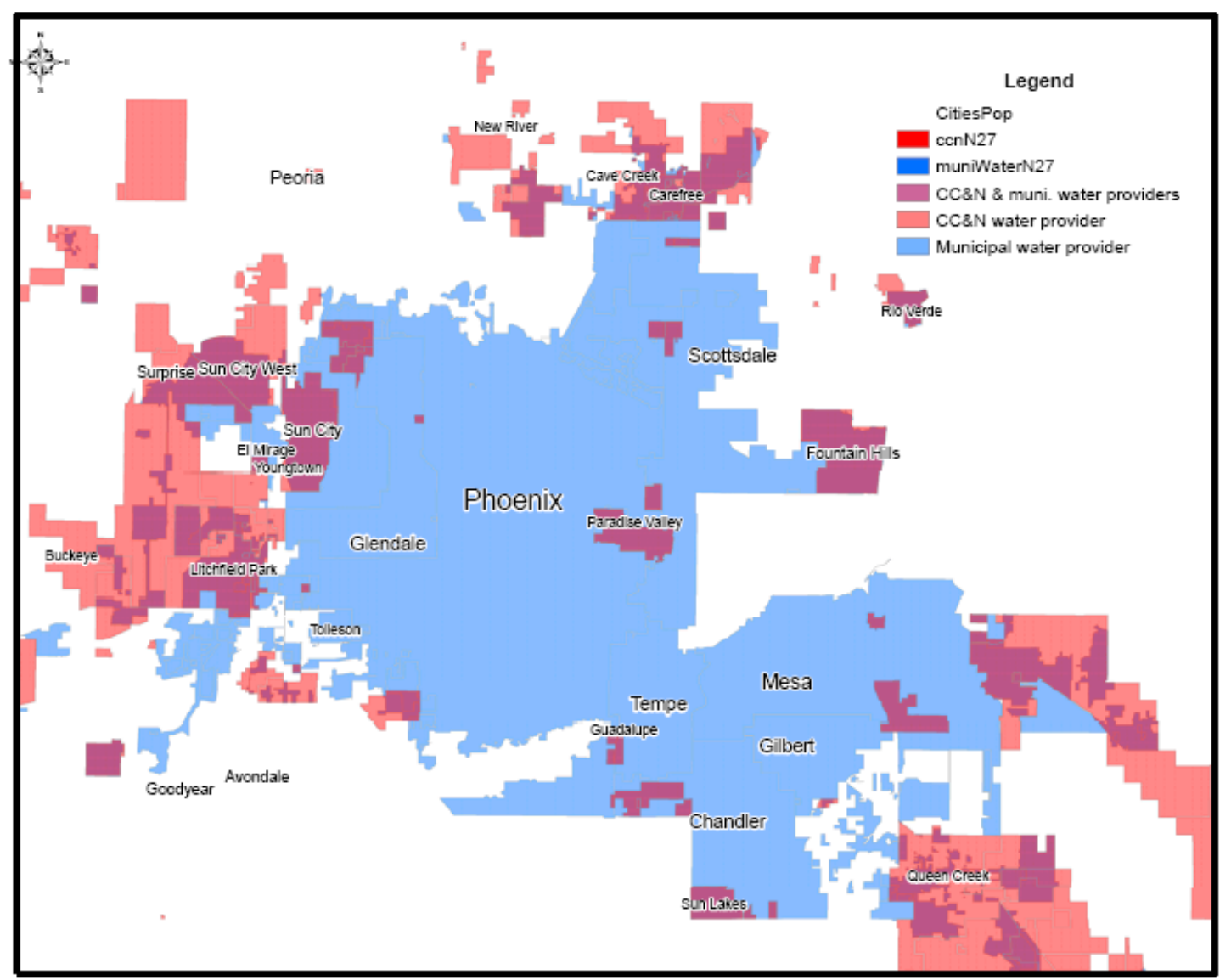

Figure 1: Water Service Providers in the Phoenix AMA 


\section{References}

Arrufat, J.L. and A. Zabalza (1986), "Female Labor Supply with Taxation, Random Preferences and Optimization Errors" Econometrica 54(1), 47-63.

Blanciforti, Laura and Richard Green (1983), "An Almost Ideal Demand System Incorporating Habits: An Analysis of Expenditures on Food and Aggregate Commodity Groups" The Review of Economics and Statistics 65(3), 511-515.

Bockstael, Nancy E. and Kenneth E. McConnell (1983), "Welfare Measurement in the Household Production Framework" American Economic Review 73 (4), 806-814.

Brown, J.N. and A.S. Rosen (1982), "On the Estimation of Structural Price Models” Econometrica 50 (3), 765-768.

Bullock, David S. and Nicholas Minot (2006), "On Measuring the Value of a Non-Market Good using Market Data," American Journal of Agricultural Economics 88(4):961-973.

Bureau of Labor Statistics (2007), "Consumer Expenditures in 2005," Report 998 U.S. Department of Labor.

Chattopadhyay, Sudip (1999), "Estimating the Demand for Air Quality: New Evidence Based on the Chicago Housing Market," Land Economics 75(Feb): 22-38.

Chetty, Raj and Adam Szeidl (2007), "Consumption Commitments and Risk Preferences” Quarterly Journal of Economics 122(2), 831-877.

Edlefsen, Lee E. (1981), “The Comparative Statics of Hedonic Price Functions and Other Nonlinear Constraints," Econometrica 49(6): 1501-1521.

Epstein, Larry G. (1981), "Generalized Duality and Integrability," Econometrica 49(May): 655-678.

Hanak, Ellen and Ada Chen (2007), "Wet Growth: Effects of Water Policy on Land Use in the American West," Journal of Regional Science 47(1): 85-108.

Hanemann, W. Michael (1984), "Discrete-Continuous Models of Consumer Demand” Econometrica 52(3), 541-561.

Hausman, Jerry A. (1978), "Specification Tests in Economics" Econometrica 52 (5), 1219-1240. 
Hausman, Jerry A. (1979), "The Econometrics of Labor Supply on Convex Budget Sets" Economics Letters 3, 171-174.

Hausman, Jerry A. (1980) "The Effect of Wages, Taxes, and Fixed Costs on Women's Labor Force Participation" Journal of Public Economics 14, 161194.

Hewitt, Julie and Michael Hanemann (1995), "A Discrete-Continuous Choice Approach to Residential Water Demand under Block Rate Pricing," Land Economics 71(2), 173-192.

La France, Jeffrey T. and W. Michael Hanemann (1989), "The Dual Structure of Incomplete Demand Systems," American Journal of Agricultural Economics 76(2): 262-274.

Mansur, Erin and Sheila Olmstead (2006), "The Value of Scarce Water: Measuring the Inefficiencies in Municipal Regulations," Working Paper.

Mendelsohn, Robert (1985), "Identifying Structural Equations with Single Market Data" Review of Economics and Statistics 67(3), 525-529.

Moffitt, Robert (1986), "The Econometrics of Piecewise-Linear Budget Constraints: A Survey and Exposition of the Maximum Likelihood Method," Journal of Business and Economic Statistics 4(3): 317-328.

Mukerji, V. (1963), "A Generalized S.M.A.C. Function with Constant Ratio of Elasticity of Substitution," The Review of Economic Studies 30(3): 233236.

Olmsted, Sheila M., W. Michael Hanemann and Robert N. Stavins (2007), "Water Demand Under Alternative Price Structures" Journal of Environmental Economics and Management, 54(2): 181-198.

Palmquist, Raymond B. (2005) "Property Value Models" in Karl-Goran Maler and Jeffrey R. Vincent, editors, Handbook of Environmental Economics, Volume 2

(Amsterdam: North Holland) pp 764-839.

Reiss, Peter C. and Matthew W. White (2006), "Evaluating Welfare with Nonlinear Prices,” NBER Working Paper No. 12370, July.

Smith, V. Kerry (1974), "Inter-temporal Production Externalities, Technical Change, and Public Expenditure Analysis," Journal of Environmental Economics and Management, 1(August):121-131. 
Taylor, Lester (2005), "Price and Income Elasticities Estimates from BLS Consumer Expenditure Surveys and ACCRA Price Data," Cardon Research Papers in Agricultural and Resource Economics, Discussion Paper 2004-14, University of Arizona, revised May 2005.

The Economist, "Not Any Drop to Drink," December 8, 2007, p. 41.

U.S. News and World Report, "Why Should You Worry About Water" June 4, 2007, p. 37-53.

Vartia, Yrjo O. (1983), "Efficient Methods of Measuring Welfare Change and Compensated Income in Terms of Ordinary Demand Functions," Econometrica 51(1):79-98.

von Haefen, Roger H. (2002), "A Complete Characterization of the Linear, Log-Linear and Semi-Log Incomplete Demand System Models," Journal of Agricultural and Resource Economics 27(December): 281-319.

von Haefen, Roger H., Daniel J. Phaneuf and George R. Parsons (2004). "Estimation and Welfare Analysis with Large Demand Systems," Journal of Business and Economic Statistics, 22(2), 194-205.

Waldman, Donald M. (2000). "A Discrete/ Continuous Choice Approach to Residential Water Demand under Block Rate Pricing: Comment." Land Economics 76(2): 322-323.

Zabalza, A. (1983) "The CES Utility Function, Non-Linear Budget Constraints and Labor Supply. Results on Female Participation and Hours" The Economic Journal 93 (June), 312-330.

Zabalza, A. and J.L. Arrufat (1988), "Efficiency and Equity Effects of Reforming the British System of Direct Taxation: a Utility-based Simulation Methodology" Economica 55(Feb), 21-45. 